\title{
Biolubricants and Triboreactive Materials for Automotive Applications
}

\author{
Amaya Igartua, Xana Fdez-Pérez, Iñaki Illarramendi, \\ Rolf Luther, Jürgen Rausch and Mathias Woydt
}

Additional information is available at the end of the chapter

http://dx.doi.org/10.5772/46852

\section{Introduction}

Replacing hydrocarbon-based oils with biodegradable products is one of the ways to reduce adverse effects on the ecosystem caused by the use of lubricants. The application of low or no sulphur, ash and phosphorous (lowSAP) ester- or polyglycol based oils are intended for passenger car engine lubricants as substitutes for hydrocarbon-based oils. The study is focused on passenger car motor oils (PCMO) with reduced metal-organic additives. This is necessary in order to reduce the ash build-up in the after treatment system and therefore improve its efficiency and lifetime. High fuel efficiency and long drain intervals are requested, as well.

In a modern diesel or Gasoline engine, the engine oils has to fulfill quite a number of different functions, such as lubricating and cooling the system, wear protection, soot and particle handling with less deposit tendency and so on.

\section{Engine oils - Developed of new passenger car motor bio oils}

\subsection{Relevant aspects of influence}

Generally speaking, engine oils consist of three major parts. The biggest part (per volume) is taken by the base fluid. It is responsible for the wear free hydrodynamic regime in lubrication and provides the basic lubricity. Besides, it serves as solvent for the additives. The additives can be subdivided into the group of surface active and lubricant active additives.

The first group consists of EP/AW-additives to reduce wear at heavily loaded tribo- contacts and so called friction modifiers (FM) that are used to reduce the coefficient of friction. These 
additives are polar and tend to adhere to the metallic surface of the engine components. Conventionally, they contain sulphur and phosphorous usually as metal-organic compounds. The other additive group is unpolar or less polar and consists of antioxidants (AO) to prolong the oil service life, dispersancy and detergency (D\&D) to keep the engine clean and soot in dispersion and of corrosion inhibitors (Ci). Metal-organic compounds are widely used in that field, the most prominent being zinc-dialkyl-dithiophosphate (ZnDTP). These three components are not independent of each other; they all contribute to overall lubricant performance. The complex interplay of the components is shown schematically in figure 1 before.

\section{- cnginc lubricants}

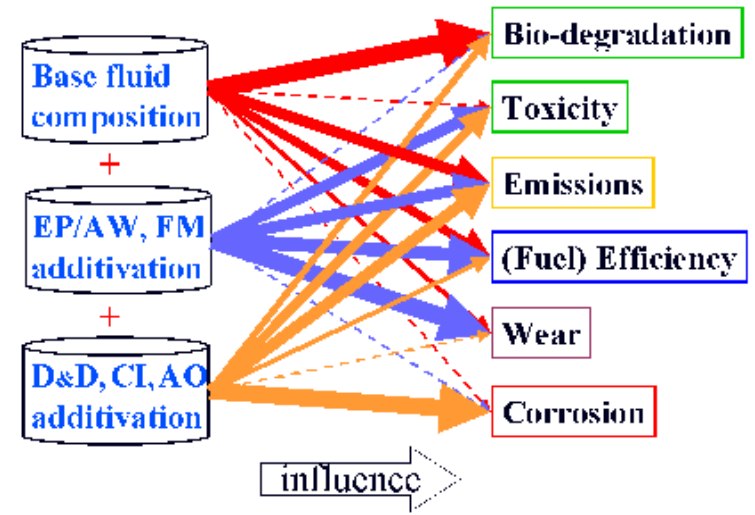

*The width of the arrows indicate the relative importance of the individual components

Figure 1. Importance of engine oil component.

\subsection{Emissions - Laboratory procedure}

One focus was the development of lubricants which are compatible with latest exhaust gas after-treatment systems. This is the reason for the desired reduction in phosphorous, sulphur and metal-organic content (expressed as sulphated ash). These elements are suspected to contribute towards catalyst poisoning and deposit formation in particle traps. However, one has to keep in mind that there are two different ways how engine oil constituents can influence the performance of after-treatment systems.

Figure 3 shows the result from the field test with a car equipped with a particle trap ('filtre à particule', FAP) and conventional engine oil. After the test the FAP was dismantled and the found deposits were analysed. Most residues were fuel related ( $\mathrm{FbA}=$ fuel based ash), but the engine oil showed an influence, too. Interesting is the comparison between metal ions found as deposits and those present in the ACEA A3/B3 engine oil. Apparently, zinc is four times more critical towards after treatment deposits than calcium. Therefore, it developed engine oils without any Zinc; even so this is the most common metal organic compound in engine oils today. 


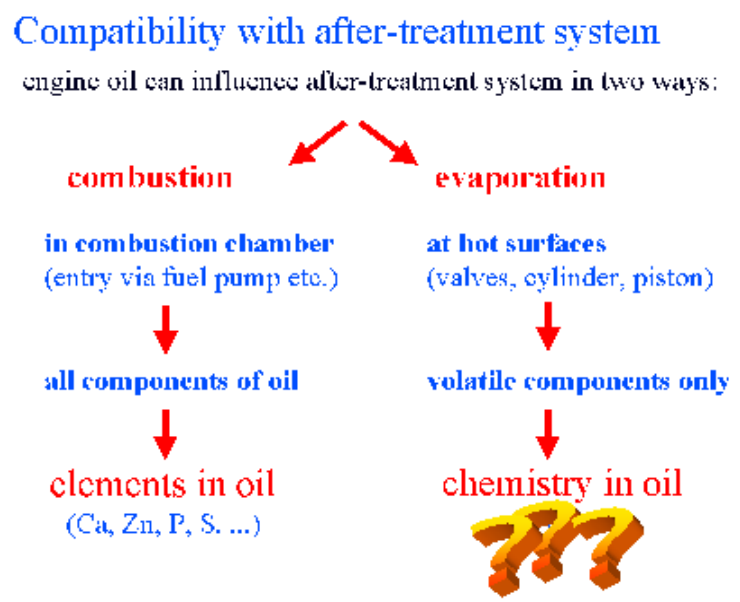

Figure 2. Engine oil composition and influence on after-treatment system.

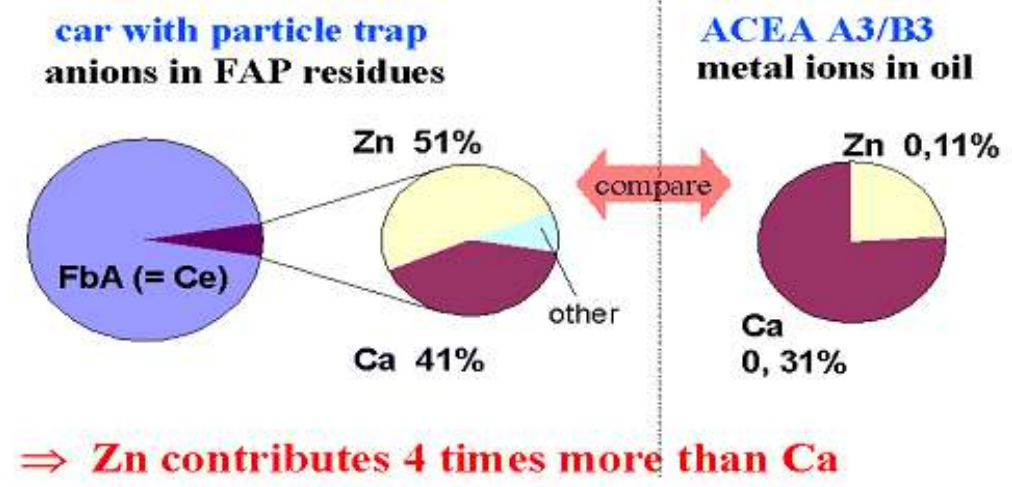

Figure 3. Analysis of residues found in particle filter (result of a field test). Zinc seems to give overproportional residues in the after-treatment system.

Some engine oil is inevitably entering the fuel path, e.g. via the fuel pumps. The fuel/engine oil mixture is then burned in the combustion chamber and all chemical elements of the engine oil are likely to reach the after treatment system. Thus, phosphorous, sulphur and sulphated ash are appropriate parameters to characterise the oil compatibility with the exhaust gas systems.

The second way of contact between engine oil and after-treatment system arises from evaporation. Hot lubricated surfaces in the engine, e.g. cylinder walls, give rise to the evaporation of volatile substances. These are not necessarily present in the fresh lubricant but may be created by thermal cracking of higher molecular weight compounds at these elevated temperatures. 
From the past, it is well known that the type of base oil has a significant influence on raw emissions. An example is the correlation between Noack evaporation loss and particle emissions (see figure 4). This correlation, together with concerns about the oil consumption led to the limitation of the Noack evaporation loss to $15 \%$ respectively $13 \%$ according to the ACEA regulation.

\section{Particle emission and evaporation loss 13-Step-Test CEC R 49 (Steyr DI-engine 9,7 ltr.)}

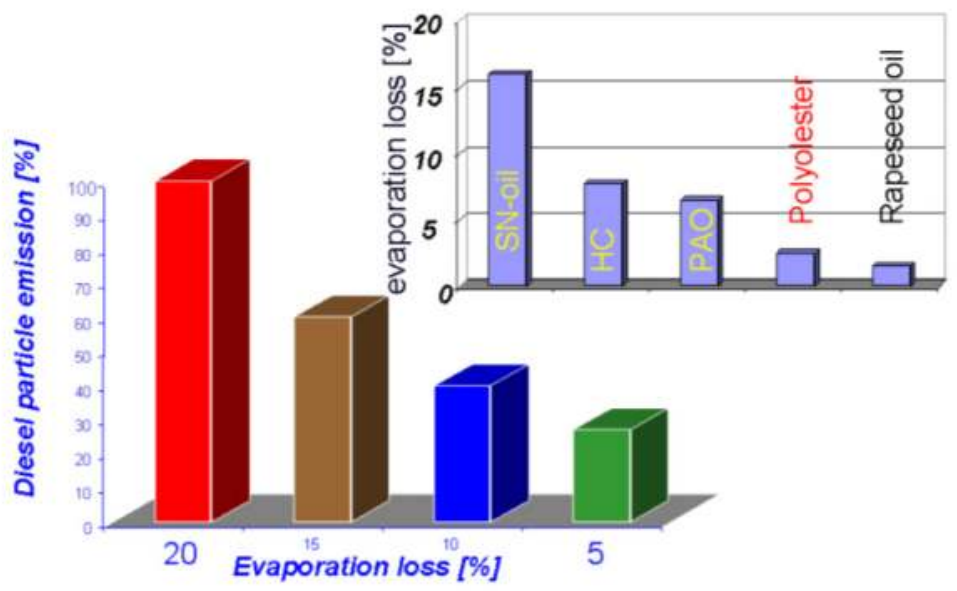

Figure 4. Correlation between Noack Evaporation loss and particle emission in a direct injection HD Diesel engine

Besides the base oil volatility, the volatility of some additives becomes interest. The content of chemical elements in the oil and their abundance in the exhaust gas need not to be proportional. For example, it is well-known that different phosphorous compounds with identical phosphorous content will show great differences in thermal stability and volatility.

In order to evaluate the element specific evaporation of fully formulated engine oils, we established a new test procedure. The new test procedure uses the Noack evaporation test equipment (DIN 51581, ASTM D5800) and the test condition $1 \mathrm{~h} @ 250^{\circ} \mathrm{C}$. However, not only the total mass loss but also the evaporation loss of additive elements is determined. A comparison of the two reference engine oils and the new candidate fluids in this test is shown in figure 5. To display hydrocarbon, sulphur and phosphorous emissions in one diagram, the test results have been normalised to a typical reference oil ( $=100 \%$ emissions).

Obviously, both developed engine oils have reduced evaporation losses compared to today's conventional oils. The hydrocarbon loss, dominated by the base oil, was cut to less than half of the original value. This should reduce the particle emission. On the additive side, sulphur and phosphorous volatility have been significantly reduced. 
Under the described conditions, volatile metal-organic compounds in significant quantities have not been found in any of the tested oils.

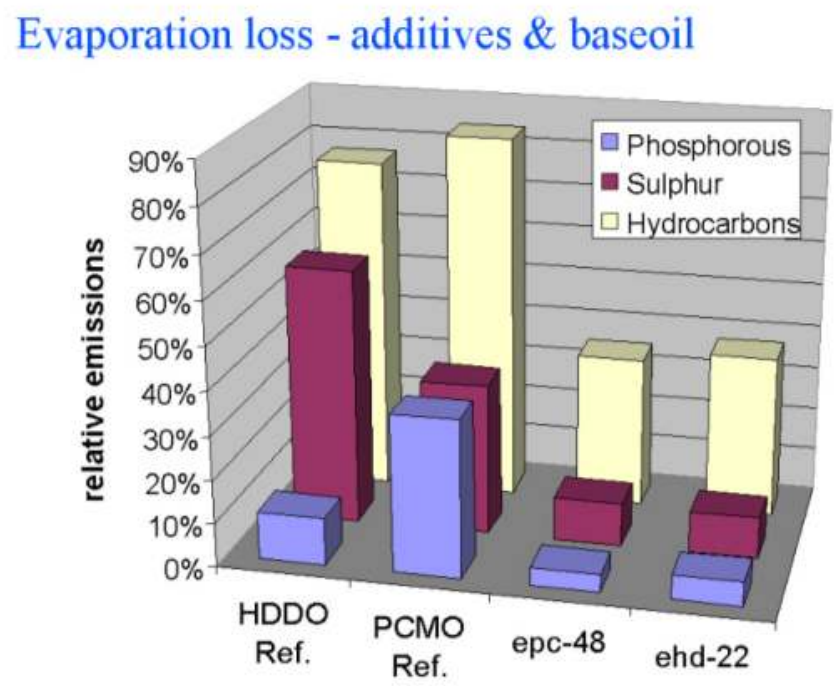

Figure 5. Element specific Noack evaporation losses (relative two reference engine oils).

\subsection{Engine cleanliness \& low ash}

The main challenge in formulating engine oils with low ash and sulphur is the question of engine cleanliness. Metal soaps and similar components (commonly called detergents) are responsible for preventing deposits in the engine, predominantly at the piston rings and groves. Besides, their alkalinity is necessary to neutralise acidic combustion products. Today, the most prominent substance used is calcium sulphonate-accounting for approximately $80 \%$ of lubricant ash and sulphur. Current engine oils have typical values of $0.3 \%$ to $0.4 \%$ Calcium, corresponding to sulphated ash contents of about $1.3 \%$ to $1.5 \%$. Thus, a reduction to $0.5 \%$ as expected by passenger car manufactures cannot be achieved by just reducing the concentration of well known additives, but needs a new additive technology.

To evaluate the capabilities of new D\&D-additives, it made intense use of the so-called Wolf-test. This test is a modification of the well known panel-coker idea. The engine oil to be tested is dropping on a hot metal plate. This steel panel is mounted at a fixed angle to allow the oil to flow down the panel slowly. At the lower end it is captured in a glass vessel to be recirculated to the panel again. After a fixed period of time the test is stopped, the panels are washed and the deposit formation is observed. Weighting and a visual rating of the panels by an expert allows judging the deposit formation tendency. 

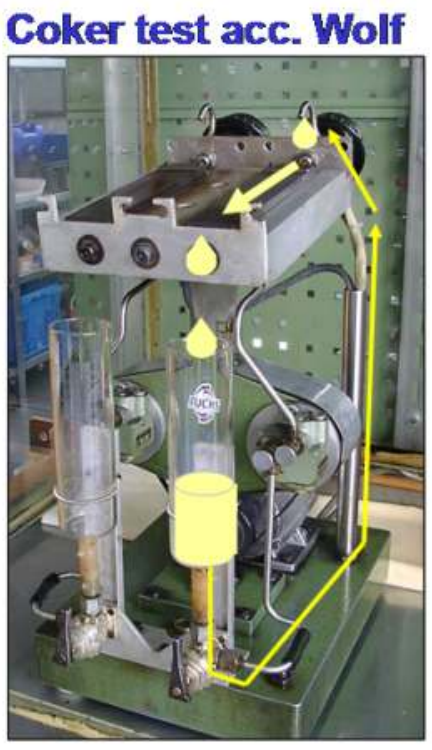

\section{6h or 12h Oil flow @ $250^{\circ} \mathrm{C}$}

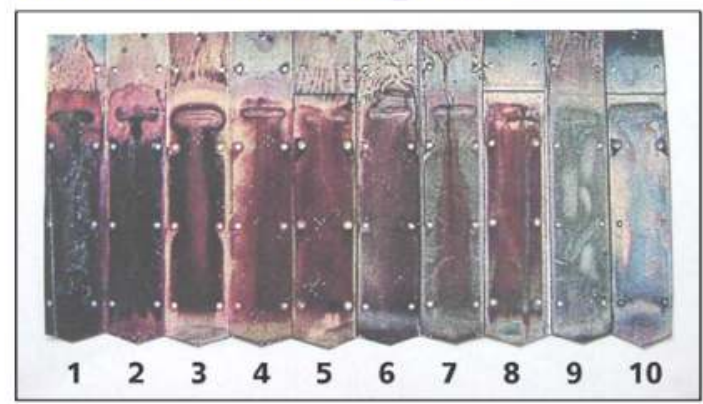

\section{Rating of plate + Amount of deposit}

Figure 6. Wolf test apparatus and sample panels showing the rating scheme.

The results obtained in the WOLF test give a good indication for engine cleanliness in real engines. Figure 7 shows the correlation between the Wolf test and the VW TDI test according to CEC L-78-T-99 as established with new oils in the past. The CEC L-78 test belongs to the ACEA sequence of engine tests and is used to rate piston cleanliness. Results greater or equal to 65 points are supposed to be good in this engine test. Thus deposits in our Wolf screening test should be below approximately 8 to $10 \mathrm{mg}$. However, only a test in a real fired engine can give reliable information about the actual performance.

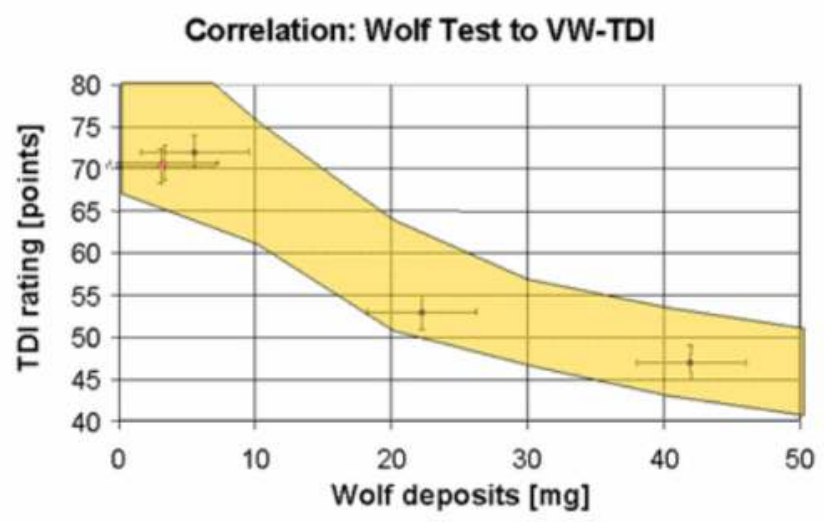

Figure 7. Correlation between screening test and actual engine test with VW TDI according to CEC L-78-99. 
As explained earlier, the major challenge in formulation the new oils is the reduction in crucial additive elements. Sulphur and phosphorous are the elements found in most antiwear agents, while the metal-organic compounds constitute important anti-oxidants and engine cleanliness additives. All three additive groups can have negative influence on the after-treatment system. Therefore so called lowSAP oils are required. The understanding of lowSAP is the reduction of sulphur ash (as a measure for metal-organic compounds) and phosphorous. The figure 8 demonstrates the comparison between the passenger motor oil reference lubricant and the new developed oils.

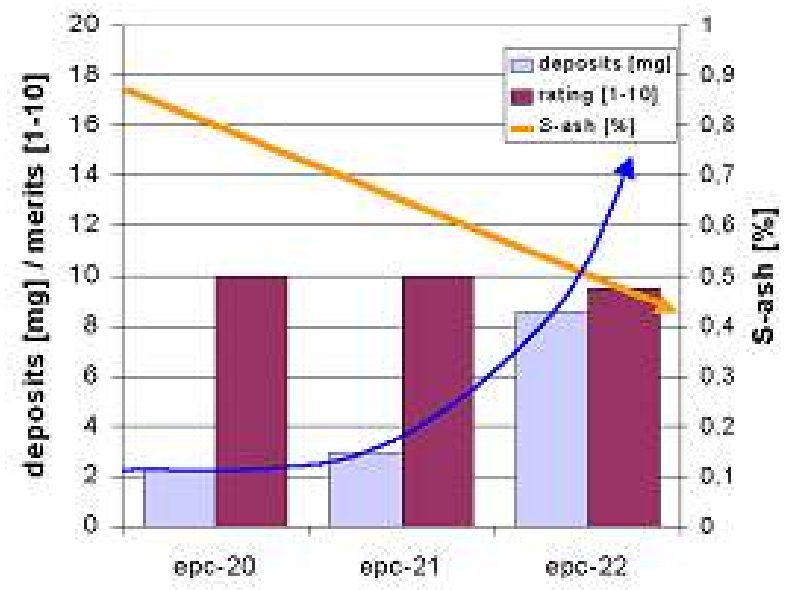

Figure 8. Results of Wolf test showing the dependency of deposit formation from the sulphated ash content of the engine oil, even with most modern technology

The (sulphur) ash content is reduced to one third, phosphorous and sulphur to less than $50 \%$ of today's product. Despite this strong decrease in metal-organic compounds, the deposit formation tendency - as screened with the panel coker test according to Wolf remains as low as the reference oil (figure 9.b). This target was reached by using a new ash less EP/AW additive technology. However, the influence of the concentration of metalorganic compounds remains visible even with newest technologies.

\subsection{PCMO - EP/AW properties}

The second concern while using lowSAP oils is wear protection. To check this performance, screening tests have been performed. Next figure 10 displays the results obtained with the SRV test rig. On the left hand side, wear scars according to DIN 51834-2 are displayed. This is a 2 hour test at constant load. Here, both new engine oils show slightly smaller wear scars. On the right hand side, results according to ASTM 5706 are displayed. In this SRV test, the load is increased in fixed intervals until seizure occurs. Higher load corresponds to a better protection at highest load spikes. The reference oil and both new candidate oils easily supersede the values typically found in engines. 

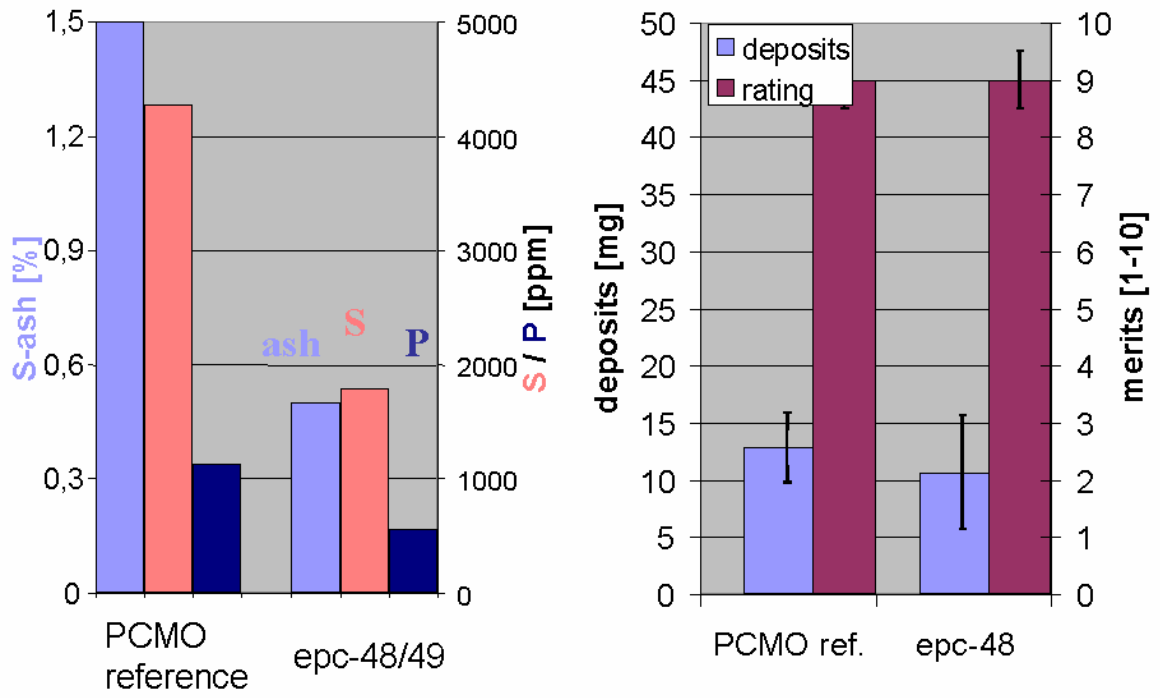

Figure 9. a) Comparison of additive elements of reference oil and epc-48 and 49 b) Wolf comparison between reference oil and epc- 48
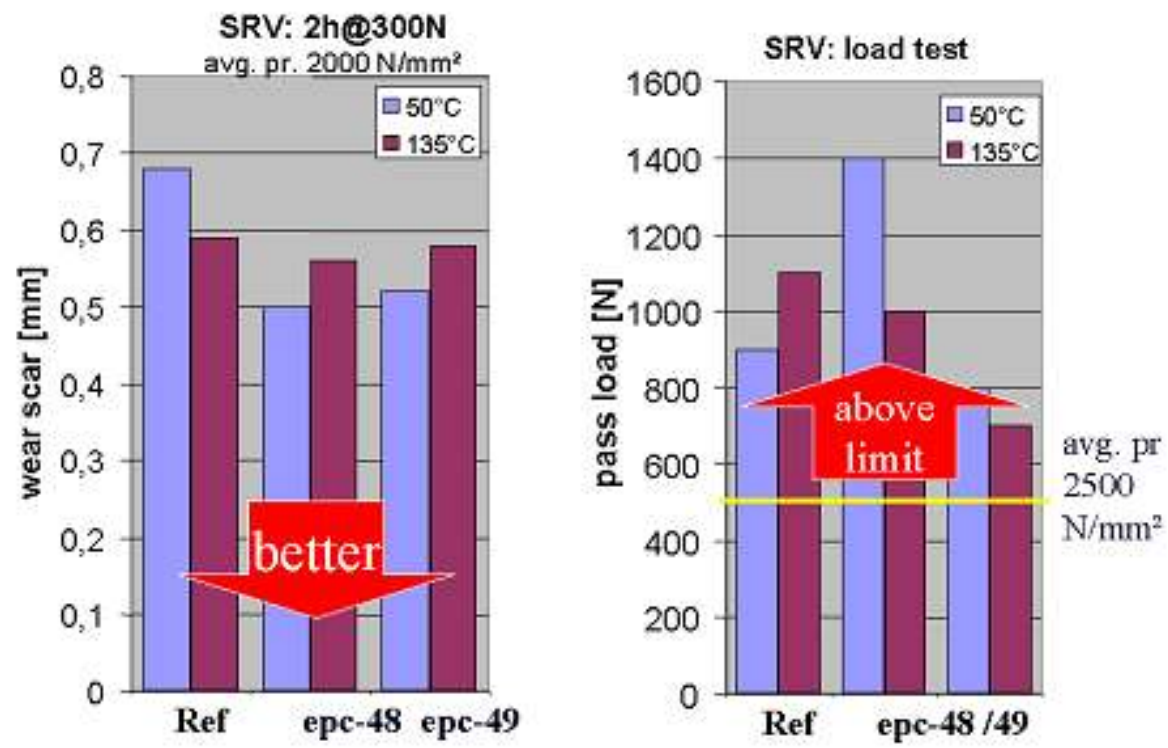

Figure 10. SRV test results for the reference oil and the new epc- 48 and epc 49 


\subsection{Fuel efficiency test}

The fuel efficiency potential of epc 50 was tested in an M111-FE engine test bench which is part of different ACEA specification. The matter of this test is to evaluate the fuel consumption under defined conditions. The fuel saving compared to the 15W40 CEC reference oil RL 191 is calculated in \%. The formidable result of 3,9\% fuel benefit demonstrate the potential of epc 50 .

\subsection{Passenger car motor oil candidates}

At least two candidate oils named epc-48 and epc-49 passes the laboratory optimization process. A comparison of the passenger car specifications and the candidate oil data is given in next table 1 .

Epc 48 and epc 49 are based on the same base fluid composition but differ in additivation. Due to their high viscosity index, the desired high temperature, high shear viscosity (HTHSV) at $150^{\circ} \mathrm{C}$ of $2.9 \mathrm{mPas}$ is reached at significantly lower viscosities at $100^{\circ} \mathrm{C}, 40^{\circ} \mathrm{C}$ and at $-25^{\circ} \mathrm{C}$. This offers the potential for improved fuel efficiency.

To meet the passenger car oil specifications, the additives and also their treat rates have to be balanced well.

\begin{tabular}{|c|c|c|c|c|}
\hline & & PCMO-Specifications & ерс-48 & ерс-49 \\
\hline SAE grade & & $0 W-30$ or $5 W-30$ & \multicolumn{2}{|c|}{ 0W-20 } \\
\hline \multirow[t]{4}{*}{ Viscosity } & kin.V. $40^{\circ} \mathrm{C}$ & $<55 \mathrm{~mm}^{2} / \mathrm{s}$ & \multicolumn{2}{|c|}{$44 \mathrm{~mm}^{2} / \mathrm{s}$} \\
\hline & kin.V. $100^{\circ} \mathrm{C}$ & $>9.3 \mathrm{~mm}^{2} / \mathrm{s}$ & \multicolumn{2}{|c|}{$8.8 \mathrm{~mm}^{2} / \mathrm{s}$} \\
\hline & CCS $-25^{\circ} \mathrm{C}$ & $<2900 \mathrm{mPas}$ & \multicolumn{2}{|c|}{$1660 \mathrm{mPas}$} \\
\hline & HTHS $150^{\circ} \mathrm{C}$ & $2,9-3,1 \mathrm{mPas}$ & \multicolumn{2}{|c|}{$2.9 \mathrm{mPas}$} \\
\hline \multicolumn{2}{|c|}{ Shear stability (Bosch) } & stay in grade & \multicolumn{2}{|c|}{ Excellent } \\
\hline \multicolumn{2}{|c|}{ Pour point } & $<-35^{\circ} \mathrm{C}$ & \multicolumn{2}{|c|}{$-45^{\circ} \mathrm{C}$} \\
\hline \multirow{3}{*}{ Elements } & $\mathrm{P}$ & $<$ 800ppm & $560 \mathrm{ppm}$ & $560 \mathrm{ppm}$ \\
\hline & $\mathrm{S}$ & $<2000$ ppm & 1800ppm & $1800 \mathrm{ppm}$ \\
\hline & $\mathrm{Zn}$ & $<500 \mathrm{ppm}$ & free & Free \\
\hline \multicolumn{2}{|c|}{ sulphated ash } & $<0,5 \%$ & $0,5 \%$ & $0,5 \%$ \\
\hline \multicolumn{2}{|c|}{ Noack evaporation loss } & $<13 \%$ & \multicolumn{2}{|c|}{$5,2 \%$} \\
\hline \multicolumn{2}{|c|}{ ICOT oxidation stability } & $140 \mathrm{~h}$ pass & \multicolumn{2}{|c|}{ O.K. } \\
\hline
\end{tabular}

Table 1. Candidate engine oils for the PCMO specification

Table 2 illustrates the developing and optimising process for passenger car motor oils regarding to oxidation stability and deposit formation tendency. 


\begin{tabular}{c|c|c|c|c|c|c} 
& epc-0 & epc-1 & epc-2 & epc-3 & epc-4 & epc-8 \\
\hline ICOT & fail & pass & fail & pass & pass & pass \\
\hline Wolf Test & pass & pass & pass & pass & n.d & n.d \\
\hline & epc-9 & epc-10 & epc-11 & epc-12 & epc-13 & epc-14 \\
\hline ICOT & fail & n.d & fail & n.d & n.d & n.d \\
\hline Wolf Test & n.d & n.d & n.d & pass & pass & pass \\
\hline & epc-15 & epc-17 & epc-18 & epc-19 & epc-20 & epc-21 \\
\hline ICOT & n.d & fail & n.d & n.d & fail & n.d \\
\hline Wolf Test & pass & n.d & n.d & n.d & pass & pass \\
\hline & epc-22 & epc-23 & epc-24 & epc-25 & epc-26 & epc-27 \\
\hline ICOT & n.d & fail & n.d & pass & pass & fail \\
\hline Wolf Test & pass & n.d & n.d & n.d & n.d & pass \\
\hline & epc-28 & epc-29-36 & epc-37 & epc-38 & epc-39 & epc-40 \\
\hline ICOT & Pass & n.d & pass & fail & pass & pass \\
\hline Wolf Test & n.d & n.d & pass & pass & pass & pass \\
\hline & epc-41-47 & epc-48 & epc-49 & epc-50 & epc-51 & epc-52 \\
\hline ICOT & n.d & pass & pass & pass & n.d & fail \\
\hline Wolf Test & n.d & pass & pass & pass & n.d & n.d \\
\hline & epc-53 & epc-54 & epc-55 & epc-56 & epc-57 & epc-58-61 \\
\hline ICOT & fail & n.d & fail & fail & fail & n.d \\
\hline Wolf Test & pass & n.d & pass & pass & pass & n.d
\end{tabular}

Table 2. Developing PCMO candidates - Optimization in oxidation stability and deposit formation tendency

One important aspect of the engine oil specification is to meet all viscosity properties according to SAE J300. During the study a change in the in SAE J300 requirements occurred. The changes relates to the low temperature cranking viscosity (CCS viscosity) and low temperature pumping viscosity (MRV). The defined measuring temperature switched to a lower value whereas the limit value was adjusted to the lower temperature.

Due to this epc 48 and epc 49 was developed in accordance to the old SAE J300 viscosity specification. Nevertheless epc 48 and 49 fulfil also the new SAE J300 low temperature requirements.

To follow a line in a consequent way, these oils have to be biodegradable and non-toxic to the aqueous environment according to the directive EC/1999/45, coherent with other international standards.

\section{Biodegradability}

Table 3 and figure 11 show results obtained with new biolubricants developed. The reference substance is an internal reference for OECD 301F biodegradation test. The passenger car motor oil (PCMO) reference was not readily biodegradable. The new PCMO developed pass the limit of biodegradation (60\% in 28 days). 


\begin{tabular}{c|c|c|c|c|c} 
Time & \multicolumn{5}{|c}{ \% Degradation } \\
\hline Day & Ref. Sust. & EPC48 (Test a) & EPC48 (Test b) & EPC 49 (Test a) & EPC 49 (Test b) \\
\hline 0 & 0 & 0 & 0 & 0 & 0 \\
\hline 7 & 90.96 & 45.11 & 37.46 & 40.76 & 41.72 \\
\hline 14 & 90.38 & 70.34 & 55.05 & 57.65 & 61.63 \\
\hline 21 & 89.50 & 81.42 & 66.13 & 66.10 & 74.06 \\
\hline 28 days & 89.50 & 87.54 & 78.36 & 76.04 & 84.00
\end{tabular}

Table 3. Results of biodegradability tests of EPC-48 and EPC- 49 samples. Fully formulated motor oils.

\section{OECD, 301F Ready Biodegradability}

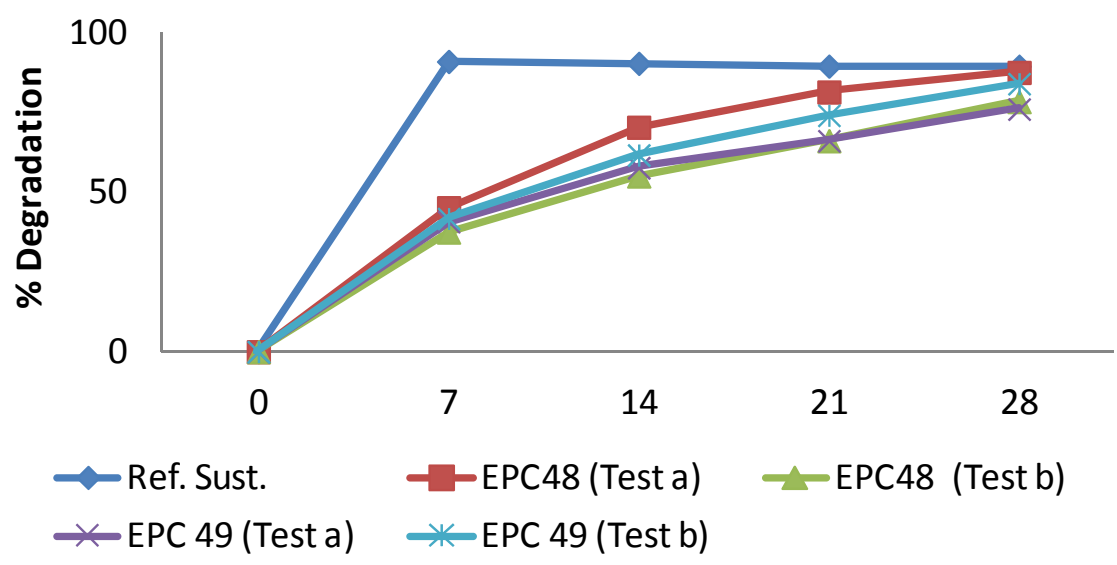

Figure 11. Results of biodegradability of EPC-48 and EPC-49 samples. Fully formulated motor oils.

Aquatic toxicity

The following basic level test are proposed and included in the EU hazard assessment of substances: Daphnia acute immobilization test (OECD 202; Table 4).

\begin{tabular}{c|c|c} 
Lubricant & *EC50 (mg/l) & Classification \\
\hline EPC-48 & EL50 $>100$ & "Not harmful" to aquatic organisms \\
\hline EPC-49 & EL50 $>100$ & "Not harmful" to aquatic organisms
\end{tabular}

*EC50: Effective Concentration. The EC50 value means the mean effective concentration of a substance that produces a particular, previously defined behaviour in $50 \%$ of the organisms of a test series.

Table 4. OECD 202, Daphnia Magna Toxicity Test Results. Fully formulated motor oils. 


\section{Definition of Tested Prototypes - Triboreactive coating for the tribo- system piston ring and cylinder liner outside of engines}

\subsection{Plasma powder characterization}

Three types of triboreactive powders were used for the production of ring prototypes. Piston rings were produced with the reference coating, CIE-TARABUSI-PL72, and with the new coatings E1, E2 and E3 with successful characteristics in terms of hardness, porosity, adherence and machine ability. In all cases an intermediate layer is applied to obtain good adherence with the substrate.

Production of plasma powder with Magnéli phases and deposition of plasma sprayed coatings containing Magnéli phases or triboactive suboxides.

Plasma powder and coating were characterized with:

- Metallography, optical microscopy and image analysis

- Profilometry

- Mastersizer for particle size distribution

- $\quad \mathrm{SEM}+\mathrm{EDX}$

- X-ray diffraction

- Raman spectroscopy

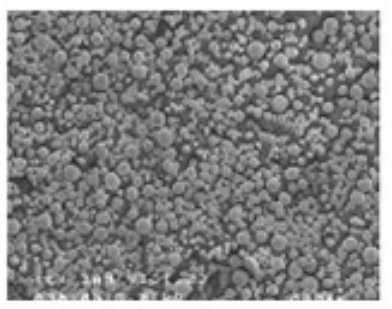

Scale: $300 \mu \mathrm{m}$

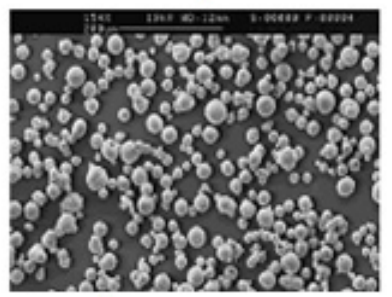

Scale: $300 \mu \mathrm{m}$

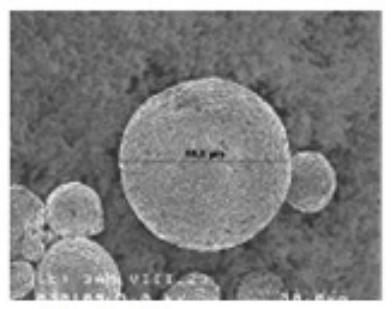

Scale: $30 \mu \mathrm{m}$

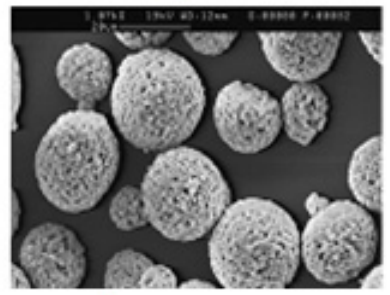

Scale: $20 \mu \mathrm{m}$

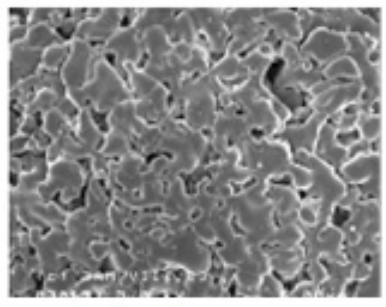

Scale: $6 \mu \mathrm{m}$

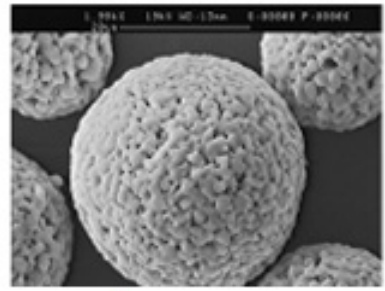

Scale: $6 \mu \mathrm{m}$

Figure 12. SEM morphology of sintered and agglomerated $\mathrm{TinO} 2 \mathrm{n}-1$ powder and $(\mathrm{Ti}, \mathrm{Mo})(\mathrm{C}, \mathrm{N})+\mathrm{Ni}+\mathrm{Mo}$ plasma powder 

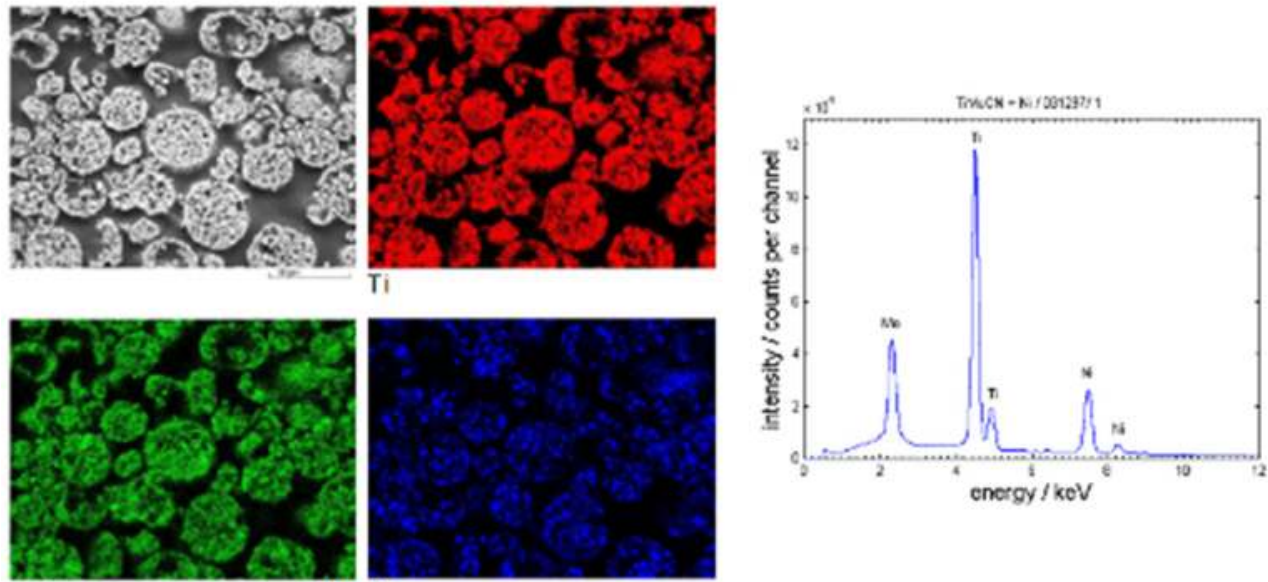

Figure 13. Cross section of $(\mathrm{Ti}, \mathrm{Mo})(\mathrm{C}, \mathrm{N})+\mathrm{Ni}+\mathrm{Mo}$ plasma powder before thermal spraying with element distribution and EDX spectrum
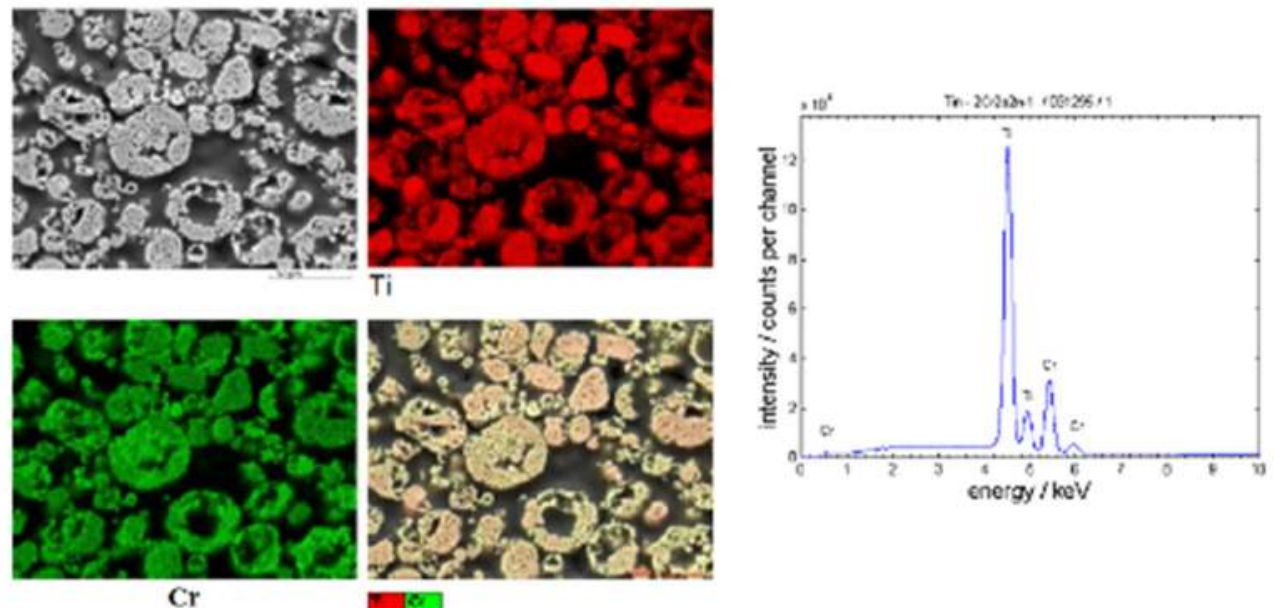

Figure 14. Cross section of Tin-2Cr2O2n-1 plasma powder before thermal spraying with element distribution and EDX spectrum 
New Advances in Vehicular Technology and Automotive Engineering

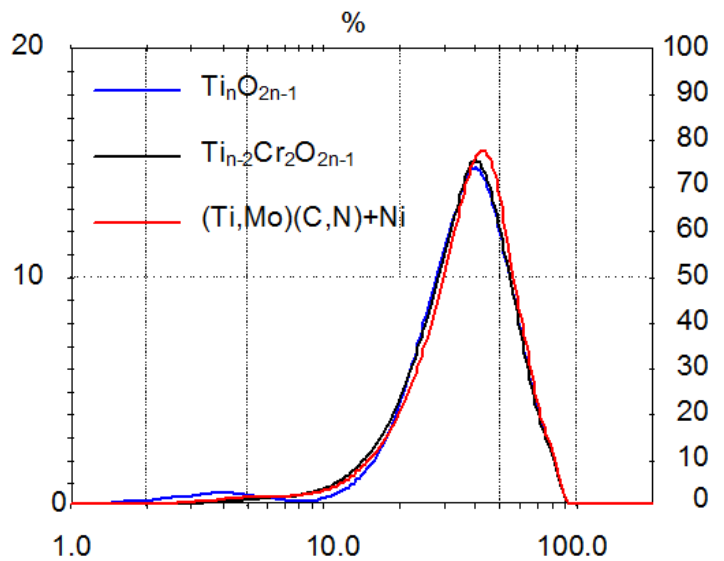

Figure 15. Particle size distribution of three plasma powders (TinO2n-1,Tin-2Cr2O2n-1 and $(\mathrm{Ti}, \mathrm{Mo})(\mathrm{C}, \mathrm{N})+\mathrm{Ni})$ without US-treatment.

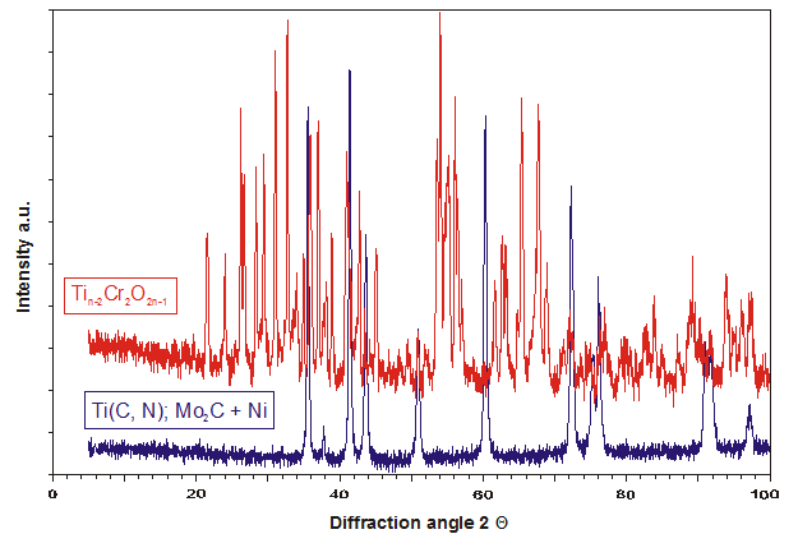

Figure 16. $\mathrm{XDR}$ spectra of $\mathrm{Ti}(\mathrm{C}, \mathrm{N}) \mathrm{Mo} 2 \mathrm{C}+\mathrm{Ni}$ and $\mathrm{Tin}-2 \mathrm{Cr} 2 \mathrm{O} 2 \mathrm{n}-1$ plasma powders
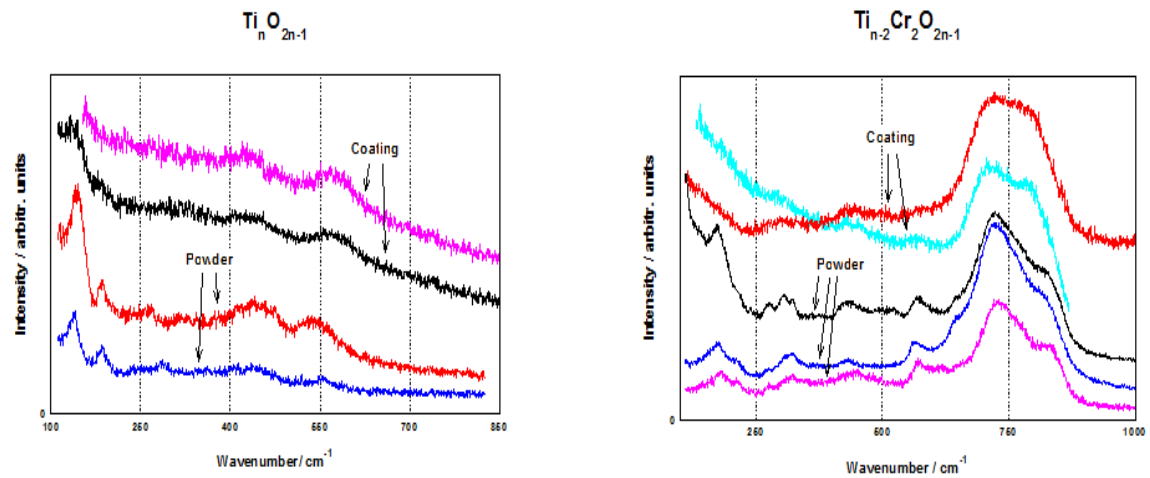

Figure 17. Raman spectra of TinO2n-1 and Tin-2Cr2O2n-1 plasma powders and plasma coatings 


\begin{tabular}{|c|c|c|c|c|c|c|}
\hline Powder & $\begin{array}{c}\text { Structure of } \\
\text { particles } \\
\text { (Metallography; } \\
\text { SEM) }\end{array}$ & \begin{tabular}{|c|} 
Grain \\
size \\
fraction \\
(FhG \\
Dresden) \\
{$[\mu \mathrm{m}]$} \\
\end{tabular} & $\begin{array}{c}\text { Particle } \\
\text { size } \\
\text { after } \\
\text { US-bath } \\
\mathrm{d} 50 \\
{[\mu \mathrm{m}]} \\
\end{array}$ & LRS & XRD & $\begin{array}{l}\text { Composition data } \\
\text { sheet (weight \%) }\end{array}$ \\
\hline $\begin{array}{l}\text { TinO2n-1 } \\
(\mathrm{n}=4 \ldots 6) \\
\text { IKTS }\end{array}$ & $\begin{array}{l}\text { Agglomerated } \\
\text { and sintered }\end{array}$ & $20-63 \mu \mathrm{m}$ & 25,01 & $\begin{array}{l}\text { TinO2n-1 } \\
(\mathrm{n}=4 \ldots 6)\end{array}$ & $\begin{array}{c}\text { Ti407 } \\
\text { Ti509 } \\
\text { Ti6011 }\end{array}$ & \\
\hline $\begin{array}{c}(\mathrm{Ti}, \mathrm{Mo})(\mathrm{C}, \mathrm{N}) \\
+\mathrm{Ni}+\mathrm{Mo}\end{array}$ & $\begin{array}{l}\text { Agglomerated } \\
\text { and sintered }\end{array}$ & $15-45 \mu \mathrm{m}$ & 22,33 & \begin{tabular}{|c} 
TiCN/ \\
TiMoCN/ \\
TiC1? \\
Ni (not \\
directly \\
measurable \\
with LRS, \\
but \\
thermally \\
induced \\
formation \\
of NiTiO3 \\
and \\
NiMoO4) \\
\end{tabular} & $\begin{array}{c}\text { TiC } \\
\text { TiC0,7N0,3 } \\
\text { [(TiMo)(CN)] } \\
\text { Ni4Ti3 } \\
\text { probably: } \\
\text { Mo2N and } \\
\text { Ni3Mo3N } \\
\text { Mo2C (very low } \\
\text { content) }\end{array}$ & $\begin{array}{c}\text { Ti 41,5-42 soll, O } \\
\text { 0,20; N 3,43; C } \\
\text { 10,09; Ni } 20 \text { soll; } \\
\text { Mo 21,5-22 soll } \\
\text { (not determined) }\end{array}$ \\
\hline $\begin{array}{c}\text { Tin- } \\
2 \mathrm{Cr} 2 \mathrm{O} 2 \mathrm{n}-1 \\
6 \leq \mathrm{n} \leq 9 \\
\text { solid } \\
\text { solution of } \\
21-23 \mathrm{~mol} \% \\
\mathrm{Cr} 2 \mathrm{O} 3 \text { in } \\
\text { TiO2 } \\
\text { HC Starck }\end{array}$ & $\begin{array}{l}\text { Agglomerated } \\
\text { and sintered }\end{array}$ & $15-63 \mu \mathrm{m}$ & 21,84 & \begin{tabular}{|c|} 
Magnéli \\
phases \\
(TinO2n-1) \\
TiO44 - and \\
CrO44 - \\
complexes - \\
Coating \\
thermal \\
stable \\
against laser \\
radiation
\end{tabular} & $\begin{array}{c}\text { Cr0.15Ti0.85O1.925 } \\
\text { Cr0.46Ti0.54O1.77 } \\
\text { Cr2Ti6O15 } \\
\text { Cr2TiO5 or } \\
\text { CrTi2O5 } \\
\text { Ti8015 }\end{array}$ & $\begin{array}{c}\text { Ti 38,2; } \mathrm{Cr} 21,8 ; \mathrm{O} \\
\text { about } 40 ; \\
\mathrm{N}<0,1 ; \mathrm{C}<0,01 ; \\
\text { Ti/Cr } \approx 1,75 \\
\text { Phases: } \\
\text { Cr0.46Ti0.54O1.77 } \\
\text { Cr0.15Ti0.85O1.925 } \\
\text { CrTi2O5; } \\
\text { Cr2Ti6O15 } \\
\text { Ti8O15 }\end{array}$ \\
\hline
\end{tabular}

* determined with thermogravimetry

Table 5. Characterisation of thermal spray powders

1: $\mathrm{TiC},(\mathrm{TiMo})(\mathrm{CN})$ and $\mathrm{TiCN}$ of cubic structure exhibit only broadened, second order Raman peaks; the detected Raman peaks can be attributed to these phases, but attribution is not unambiguous.

- $\quad$ TinO2n-1 powder $(n=4-6)$ is not stable against thermal stress.

- Atmospheric plasma spraying as well as laser radiation cause oxidation with increasing formation of rutile. With APS process Magnéli phases cannot be fully transferred from the TinO2n-1 spray powder to the APS coatings.

- Magnéli phases are stabilized against thermal stresses, laser radiation and oxidation, if chromium oxide was added to TinO2n-1. 
- Both, Tin-2Cr2O2n-1 powder and thermal sprayed coating contain high amount of stable H-Magnéli phases. Tin-2Cr2O2n-1 can be sprayed with APS to produce triboactive coatings.

- Vacuum plasma spraying (VPS) in reducing gas atmospheres using hydrogen addition to plasma gas allows to produce coatings with Magnéli phases. With VPS process Magnéli phases of TinO2n-1 ( $n=4-6$; IKTS) powder can be transferred to the coatings. Additionally, other Magnéli phases were detected with XRD.

- The substoichiometry and electric conductivity of TiO2- $x$ can be effected by the amount of hydrogen in plasma gas. Substoichiometry and electric conductivity increase with the amount of hydrogen in plasma gas as reducing medium.

- Magnéli phases were found with LRS and XRD.

- Owing to the stability of the Tin-2Cr2O2n-1 powder, thermal sprayed coatings with stable Magnéli phases can be produced with APS process - using Ar/He process gas mixture with $\mathrm{Ar}=35$ SLPM and H2 $=8$ SLPM.

- $\quad$ Thermal sprayed $(\mathrm{Ti}, \mathrm{Mo})(\mathrm{C}, \mathrm{N})+\mathrm{Ni}+\mathrm{Mo}$ coatings have been produced with HVOF and plasma spraying process.

- Thermal sprayed coatings (Ti- and TiCr-suboxides with crystallographic planar defect structure (Magnéli phases)) on flat disks have been produced for prescreening tribotests and evaluation of interactions of different lubricant / coating combinations.

\subsection{Piston ring prototypes}

\begin{tabular}{c|c|c|c|c}
\multirow{2}{*}{ Part Name } & \multicolumn{2}{|c|}{ Dimensions } & Material & Coating \\
\cline { 2 - 3 } & Nominal Ø & Height & Perlitic cast iron AT182 & - \\
\hline Cylinder Liner & 96 & - & & PL72 \\
\hline \multirow{2}{*}{ Top piston Ring } & 96 & 2 & Nodular graphite cast iron AT126 & PL E1 \\
\cline { 3 - 5 } & & & & PL E2 \\
\cline { 4 - 5 } & & & & PL E3
\end{tabular}

Table 6. System/Component Definition

\begin{tabular}{c|c|c|c|c} 
& $\begin{array}{c}\text { PL E3 } \\
\mathrm{TinO}_{2 \mathrm{n}-1}\end{array}$ & $\begin{array}{c}\text { PL E1 } \\
\mathrm{Tin}_{\text {-2 }} \mathrm{Cr}_{2} \mathrm{O}_{2 \mathrm{n}-1}\end{array}$ & $\begin{array}{c}\text { PL E2 } \\
(\mathrm{Ti}, \mathrm{Mo})(\mathrm{C}, \mathrm{N})+23 N i M o \\
\text { 1.batch }\end{array}$ & $\begin{array}{c}\text { PL E2 } \\
(\mathrm{Ti}, \mathrm{Mo})(\mathrm{C}, \mathrm{N})+23 N i M o \\
\text { 2.batch }\end{array}$ \\
\hline Argon pressure (psi) & 50 & 50 & 50 & 50 \\
\hline Hydrogen pressure (psi) & 25 & 25 & 25 & 25 \\
\hline Electric intensity (A) & 575 & 575 & 575 & 575 \\
\hline Distance to part (mm) & 110 & 110 & 110 & 110 \\
\hline Carrying gas pressure (rpm) & 20 & 20 & 20 & 20 \\
\hline Part rotating speed (rpm) & 300 & 300 & 300 & 10 \\
\hline Gun feed (mm/s) & 10 & 10 & 10 & 11,5
\end{tabular}

Table 7. Process parameters of atmospheric spraying of triboactive coatings on piston rings. 
The characteristics of the coatings, as porosity, hardness adherence and light tightness, are collected in table below.

\begin{tabular}{|c|c|c|c|c|}
\hline Feature & PL72 & PL E3 & PL E2 (Batch 2) & PL E1 \\
\hline & Reference & $\mathrm{TinO}_{2 \mathrm{n}-1}$ & $(\mathrm{Ti}, \mathrm{Mo})(\mathrm{C}, \mathrm{N})+23 \mathrm{NiMo}$ & $\mathrm{Tin}-2_{2} \mathrm{Cr}_{2} \mathrm{O}_{2 \mathrm{n}-2}$ \\
\hline Process & \multicolumn{4}{|c|}{$\begin{array}{l}\text { Casting Rough machining APSpraying OS grinding Sides grinding Face honing } \\
\text { Gap-milling }\end{array}$} \\
\hline $\begin{array}{l}\text { Adherence to } \\
\text { substrate }\end{array}$ & \multicolumn{4}{|c|}{ By means of intermediate layer } \\
\hline $\begin{array}{c}\text { Incidents by } \\
\text { manufacturing }\end{array}$ & $\begin{array}{c}\text { Normal } \\
\text { behaviour }\end{array}$ & $\begin{array}{c}\text { The coating } \\
\text { wears off very } \\
\text { easily by } \\
\text { honing. The } \\
\text { coating breaks } \\
\text { by gap milling }\end{array}$ & $\begin{array}{l}\text { Highly porous layer. } \\
\text { Barrel shape hard to } \\
\text { recognize due to high } \\
\text { roughness. Easy to } \\
\text { machine }\end{array}$ & Normal behaviour \\
\hline $\begin{array}{l}\text { Porosity of } \\
\text { coatings }\end{array}$ & $5 \%$ & $2 \%$ & $10 \%$ & $5 \%$ \\
\hline $\begin{array}{l}\text { Hardness } \\
\text { (HV0.5) }\end{array}$ & $450-480$ & $631-670$ & $640-660$ & $522-554$ \\
\hline $\begin{array}{l}\text { Roughness } \\
\text { Rpk }(\mu \mathrm{m})\end{array}$ & 0.2 & $0.15-0.32$ & $0.37-1.09$ & $0.19-0.25$ \\
\hline Thickness $(\mu \mathrm{m})$ & $\sim 250$ & $>50$ & $\sim 200$ & $\sim 250$ \\
\hline Adherence & Good & Good & Fair & Good \\
\hline Light tightness & & & Good & \\
\hline
\end{tabular}

Table 8. Summary of properties of atmospheric plasma sprayed triboactive coatings on piston rings.

\section{Reference Components:}

These components were designed and manufactured by CIE-TARABUSI with own knowledge and technology.

Piston: Design for Turbo Diesel application with oil cooling gallery and steel struts for expansion control, in aluminum alloy AT12 with $12 \%$ silicon content and iron insert for the top groove improved wear resistance. The piston head is coated by hard anodizing to avoid thermal cracks. The piston skirt has a graphite coating to improve lubrication during runningin. Basic dimensions: Diameter $96 \mathrm{~mm}$, Total height $87.2 \mathrm{~mm}$, Compression height $50.45 \mathrm{~mm}$.

1st ring: Plasma sprayed PL-72 rings in spheroidal cast iron material AT126, heat treated martensitic, ISO 6621/3MC 53 type, of diameter $96 \mathrm{~mm}$ and height of $2 \mathrm{~mm}$. Pl-72 ring is high wear and scuffing resistant coating made up by Molybdenum, Molybdenum carbide and Nickel-Chromium compounds widely used in powered Diesel applications, where Chromium coatings cannot be used due to the elevated temperature of the engine.

2nd ring: Chromium plated taper ring with conical periphery and positive torsion internal step, manufactured in STD material AT110, non heat treated gray cast iron, ISO 6621/3 MC 11 type, of diameter $96 \mathrm{~mm}$ and $2 \mathrm{~mm}$ height 
3rd ring: Chromium plated helicoidal spring loaded oil control ring with symmetric bevels, produced in STD material AT110 non heat treated gray cast iron, ISO 6621/3 MC 11 type. The helicoidal spring is made of oil hardened spring steel, of $96 \mathrm{~mm}$ of diameter and $3 \mathrm{~mm}$ of height.

Pin: DIN 17Cr3 carburized, hardened and tempered steel pin, with $30 \mathrm{~mm}$ of outer diameter, $15 \mathrm{~mm}$ of inner diameter and $80 \mathrm{~mm}$ length.

E1: Top ring coated with titanium chromium oxide

Top ring: As the reference ring but coated by atmospheric plasma with E1 powder developed. The composition of the powder is given below:

E1: Tin-2Cr2O2n-1, $6 \leq \mathrm{n} \leq 9,21-23 \mathrm{~mol} \% \mathrm{Cr} 2 \mathrm{O} 3$, Magnéli phases sintered and

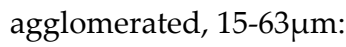

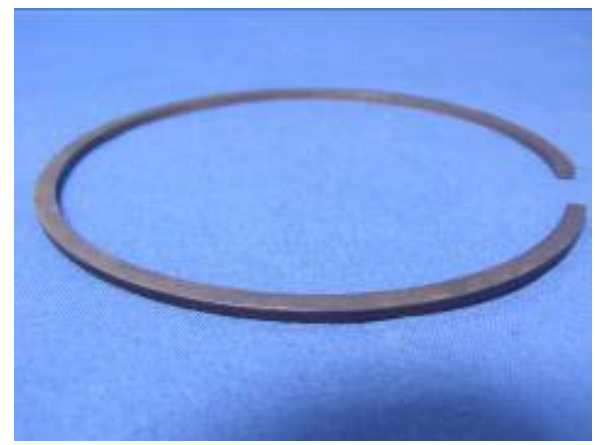

Figure 18. Prototype E1: Tin-2Cr2O2n-1,

E2: Top ring coated with titanium-molybdenum carbide-nitrides

Top ring: As the reference ring but coated by atmospheric plasma with E2 powder developed. The composition of the powder is given below:

E2: $77(\mathrm{Ti}, \mathrm{Mo})(\mathrm{C}, \mathrm{N})-20 \mathrm{Ni}-3 \mathrm{Mo}, \mathrm{Ti} / \mathrm{Mo}$ ratio $\approx 2: 1$, sintered and agglomerated:

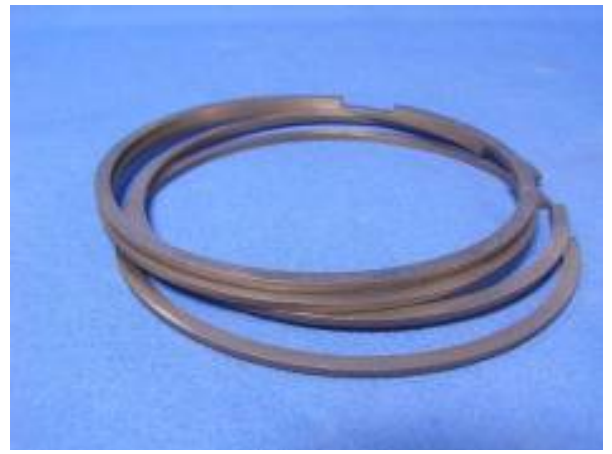

Figure 19. Prototype E2: 77 (Ti,Mo) $(\mathrm{C}, \mathrm{N})-20 \mathrm{Ni}-3 \mathrm{Mo}$ 
E3: Top ring coated with titanium oxide

Top ring: As the reference ring but coated by atmospheric plasma with E1 powder developed. The composition of the powder is given below:

E3: TinO2n-1 (Ti4O7, Ti5O9, Ti6O11) sintered and agglomerated, 20-63 $\mu \mathrm{m}$ :

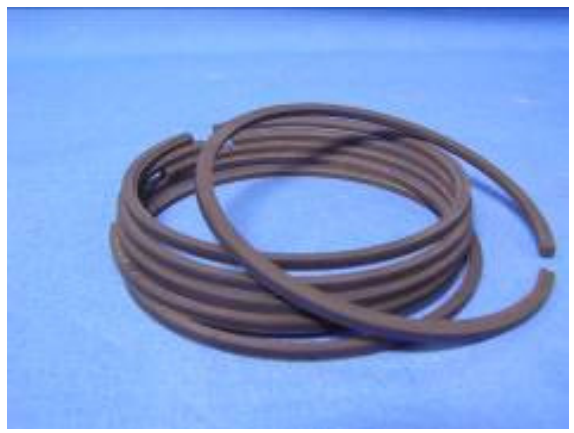

Figure 20. Prototype E3: TinO2n-1

\section{Friction and wear simulation tests. Combining bio oils with triboreactive coatings}

\subsection{Piston ring cylinder liner simulation}

To study these new oils have been tested different piston rings coated with triboreactive powders deposited by Plasma spray against cast iron cylinder liner, using the PCMO oil as reference. In the next figure 21, the configuration to carry out the simulation tests developed by TEKNIKER is shown.

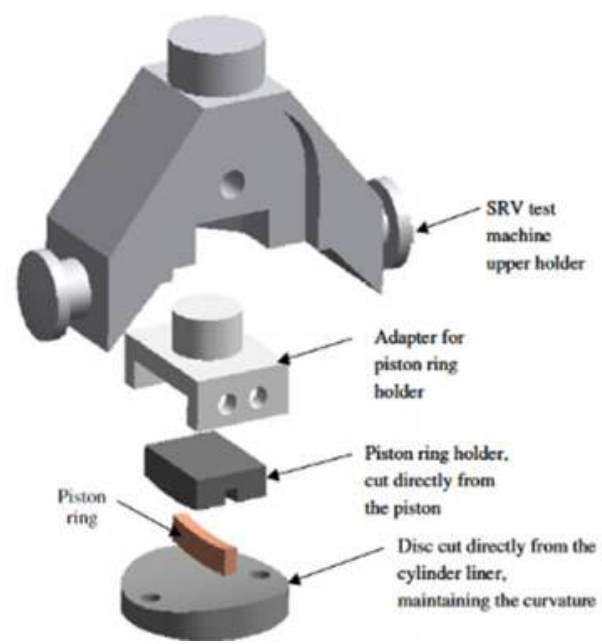

Figure 21. Cylinder liner-Piston ring configuration test. 
The test conditions were:

Load and time:

- $\quad 41 \mathrm{~min}$, load: $50 / 2000 \mathrm{~N}$ in scuffing tests. The load is increased in fixed intervals until seizure occurs. Higher load corresponds to a better protection at highest load spikes.

- 90minutes and 300N in Wear Test,

The rest of the conditions are similar in both tests: frequency: $50 \mathrm{~Hz}$, stroke: $3 \mathrm{~mm}$, temperature: $200^{\circ} \mathrm{C}$.

\begin{tabular}{|c|c|c|c|c|}
\hline \multirow[b]{2}{*}{ Piston rings } & \multirow[b]{2}{*}{ Oil } & \multicolumn{3}{|c|}{ Extreme Pressure Conditions } \\
\hline & & $\begin{array}{c}\text { Time at which } \\
\text { failure occurs } \\
\text { (minutes) }\end{array}$ & $\begin{array}{l}\text { The highest friction } \\
\text { load at which no } \\
\text { failure occurs }(\mathrm{N})\end{array}$ & Type of failure* \\
\hline Chrome plated & \multirow{3}{*}{ Ref. } & 28 & 1300 & Stroke $<0,3 \mathrm{~mm}$ \\
\hline $\mathrm{E} 3: \mathrm{TinO}_{2 \mathrm{n}-1}$ & & 36 & 1800 & Stroke $<0,3 \mathrm{~mm}$ \\
\hline E1:Tin-2 $\mathrm{Cr}_{2} \mathrm{O}_{2 \mathrm{n}-1}$ & & 29 & 1400 & Stroke $<0,3 \mathrm{~mm}$ \\
\hline Chrome plated & \multirow{3}{*}{$\begin{array}{c}\text { EPC- } \\
48\end{array}$} & 30 & 1400 & Stroke $<0,3 \mathrm{~mm}$ \\
\hline $\mathrm{E} 3: \mathrm{TinO}_{2 \mathrm{n}-1}$ & & 32 & 1600 & Stroke $<0,3 \mathrm{~mm}$ \\
\hline $\mathrm{E} 1: \mathrm{Tin}_{2} \mathrm{Cr}_{2} \mathrm{O}_{2 \mathrm{n}-1}$ & & 41 & 2000 & No failure \\
\hline \multirow{2}{*}{ Chrome plated } & \multirow{5}{*}{$\begin{array}{c}\text { EPC- } \\
49\end{array}$} & 32 & 1500 & Stroke $<0,3 \mathrm{~mm}$ \\
\hline & & 31 & 1500 & Stroke $<0,3 \mathrm{~mm}$ \\
\hline \multirow{2}{*}{ E3:TinO2n-1 } & & 36 & 1800 & Stroke $<0,3 \mathrm{~mm}$ \\
\hline & & 38 & 1900 & Stroke $<0,3 \mathrm{~mm}$ \\
\hline E1:Tin-2 $\mathrm{Cr}_{2} \mathrm{O}_{2 \mathrm{n}-1}$ & & 41 & 2000 & No failure \\
\hline
\end{tabular}

*The failure is considered when the first micro-welding appears.

Table 9. Cylinder liner-Piston ring Test Results.- Scuffing Results

\begin{tabular}{|c|c|c|c|}
\hline \multirow{2}{*}{ Piston rings } & \multirow{2}{*}{ Oil } & \multicolumn{2}{|c|}{ Wear Conditions } \\
\hline & & Friction coefficient & Cylinder liner mass lost (mg) \\
\hline Chrome plated & \multirow{3}{*}{ Ref. } & 0.11 & 0.4 \\
\hline $\mathrm{E} 3: \mathrm{TinO}_{2 \mathrm{n}-1}$ & & 0.12 & 0.2 \\
\hline $\mathrm{E} 1: \mathrm{Tin}_{\mathrm{n}-2} \mathrm{Cr}_{2} \mathrm{O}_{2 \mathrm{n}-1}$ & & 0.11 & 0.4 \\
\hline Chrome plated & \multirow{3}{*}{ EPC-48 } & 0.13 & 0.3 \\
\hline $\mathrm{E} 3: \mathrm{TinO}_{2 \mathrm{n}-1}$ & & 0.14 & 0.0 \\
\hline $\mathrm{E} 1: \mathrm{Tin}_{\mathrm{n}-2} \mathrm{Cr}_{2} \mathrm{O}_{2 \mathrm{n}-1}$ & & 0.13 & 0.3 \\
\hline Chrome plated & \multirow{3}{*}{ ЕРC-49 } & 0.13 & 0.6 \\
\hline $\mathrm{E} 3: \mathrm{TinO}_{2 \mathrm{n}-1}$ & & 0.14 & 0.2 \\
\hline $\mathrm{E} 1: \mathrm{Tin}_{-2} \mathrm{Cr}_{2} \mathrm{O}_{2 \mathrm{n}-1}$ & & 0.14 & 1.5 \\
\hline
\end{tabular}

*The roughness of $\mathrm{E} 2 \mathrm{77}(\mathrm{Ti}, \mathrm{Mo})(\mathrm{C}, \mathrm{N})-20 \mathrm{Ni}-3 \mathrm{Mo}$ are very high, so these piston rings will not be tested in laboratory simulation.

Table 10. Cylinder liner-Piston ring Test Results.- Friction and Wear Results

Also, the new oils developed (EPC-48 and EPC-49) have similar or better behaviour than the PCMO reference oils. It seems that the combination triboreactive coating/polar lubricant increases the load carrying capacity and the extreme pressure properties. 


\subsection{Specific wear energy}

Specific wear energy is a criterion, which takes both into account: it is the ratio of the friction work spent in the interface divided by the mass loss due to the wear.

$$
\mathrm{E}_{\mathrm{w}}=\frac{E}{\Delta m}=\frac{v_{m} F_{N} \int_{t i}^{t f} \mu_{f r}(t) d t}{\Delta m}
$$

The specific wear energy Ew is the amount of energy needed to wear a certain mass of matter. Consequently, the higher the value of the $\mathrm{Ew}$ is, the more difficult it is to wear the material.

The Figures 22 and 23 show the cylinder liner wear specific energy.

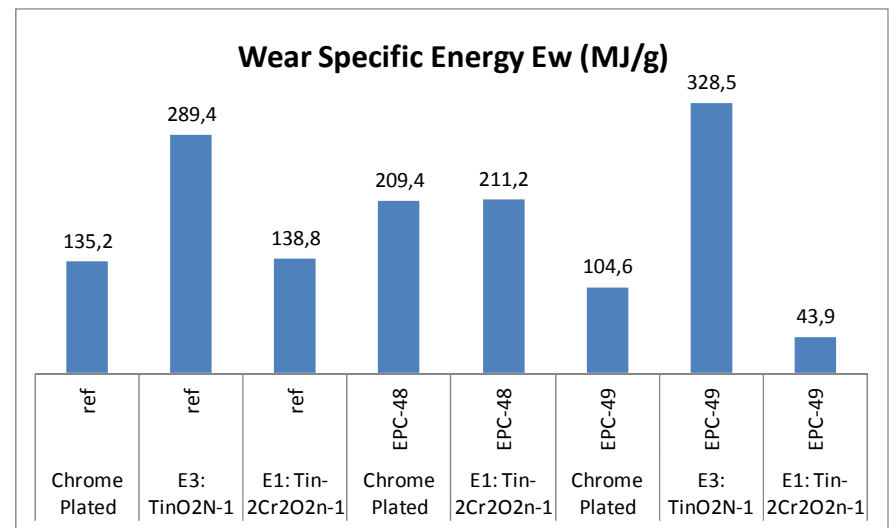

Figure 22. Cylinder liner wear specific energy. Friction and Wear Simulation Tests.

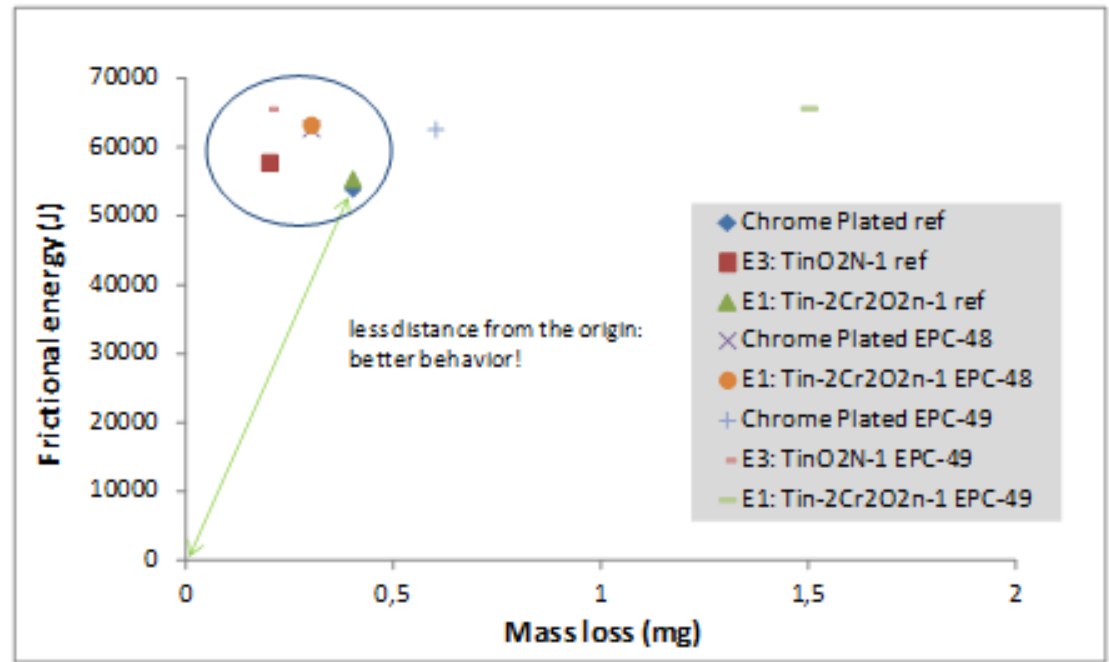

Figure 23. Frictional energy/mass lost. Friction and Wear Simulation Tests. 


\section{Engine tests. Pass/No pass results for biodegradable fluids in combination with triboreactive materials. Evaluation of friction, wear, life, oil consume}

The piston ring component engine tests have been performed by CIE TARABUSI in a $2.7 \mathrm{~L}$ turbo-charged 4-stroke diesel engine, using as reference the Mo-based plasma coating PL72 (reference used by CIE-Tarabusi).

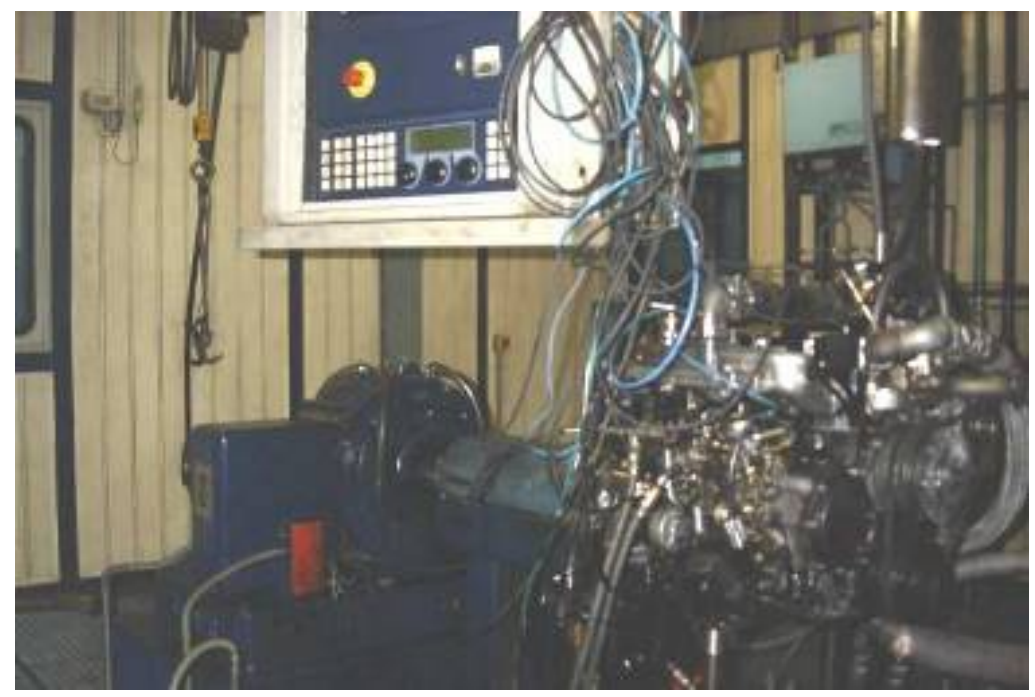

Figure 24. Testing of piston rings in a turbo diesel engine arrangement

The test conditions and parameters were fixed for three different type of tests: (a) Scuff test to determine the scuffing resistance of the coating at high temperature and pressure with minimum component clearance, (b) Hot test, long run at high power and high speed to set the reference values for wear and (c) Cycle test between low and high thermal conditions to determine the thermal fatigue and adherence resistance of the developed coatings. The components were measured before and after the test.

\subsection{Tests results}

The pistons and rings are inspected visually after the scuff, life tests and cyclic tests. The appearance observations of the tested components are presented comparatively to the reference components. We summarized the aspect of the prototypes as follows.

\section{Reference components}

The piston has good appearance for the time of running and type of tests run. The wear pattern of the piston skirt is smooth and wide. The rings have normal periphery and side wear. The pin also has a typical appearance with normal signs of friction effects. 


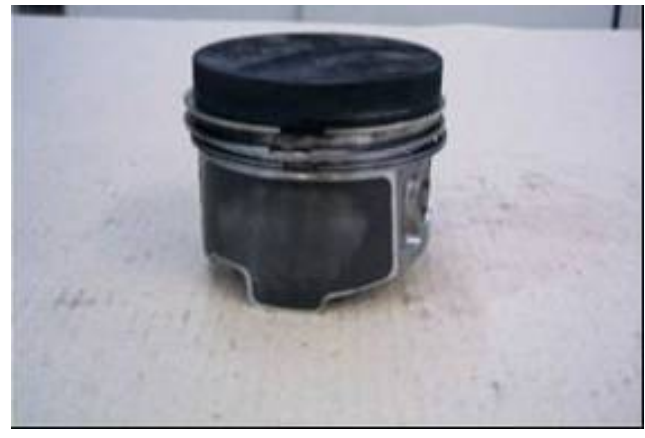

Thrust Side

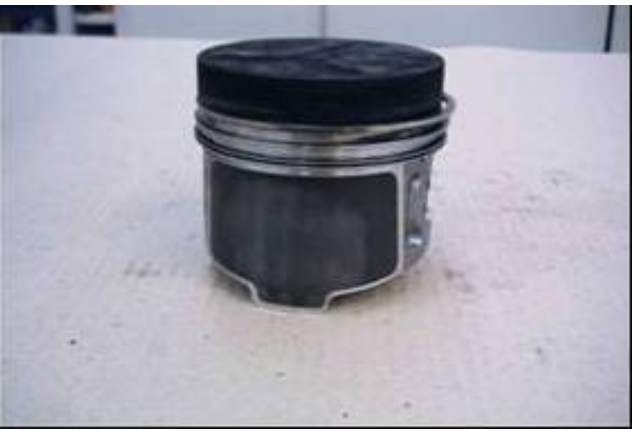

Anti-thrust Side

Figure 25. Testing of Piston Rings with reference coating and reference oil

\section{E1, E2 and E3 coated top Rings}

E2 and E3 coatings have good appearance as it is the case for the reference rings. Coating E1, on the contrary, breaks off during the tests. The picture below shows the periphery of the coated rings.

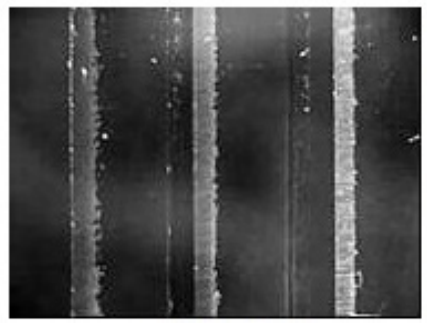

E3: TinO2n-1

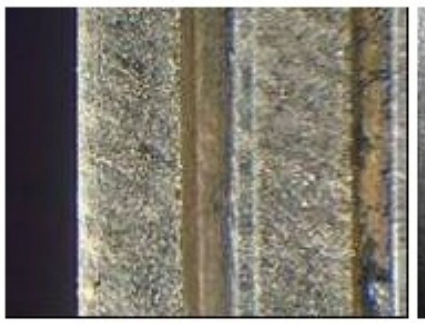

E2: $(\mathrm{Ti}, \mathrm{Mo})(\mathrm{C}, \mathrm{N})+\mathrm{Ni}+\mathrm{Mo}$

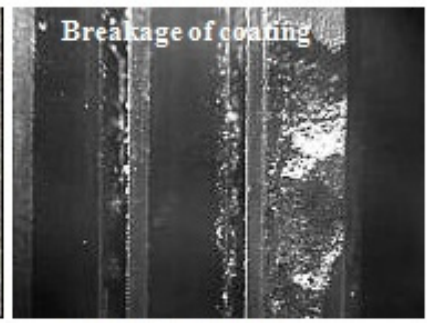

E1: Tin-2Cr2O2n-1

Figure 26. Engine Tests.- Testing of piston rings with triboreactive coatings, aspect of parts after test with standard oil

The engine test results are as follows:

1) Reference engine test: The studied tribological pair is the cylinder liner of $96 \mathrm{~mm}$ internal diameter and made of uncoated pearlitic cast iron AT182 and top piston rings of $96 \mathrm{~mm}$ outside diameter, height $2 \mathrm{~mm}$ and made of nodular graphite cast iron AT126 coated with PL72 standard atmospheric plasma layer. The results are the reference for wear, scuff resistance and adherence. Engine oil consumption and blow-by values are also considered for comparison.

These tests were performed with the reference materials and using the oil SAE 5W30. The scuffing test $(2 \mathrm{~h} 30 \mathrm{~m})$ was done with $100 \%$ load and speed engine conditions. Water and oil temperatures were measured. Neither piston nor piston rings show scuff marks after 
testing. Concerning hot test $(100 \mathrm{~h})$, the engine conditions were $105 \%$ load, $100 \%$ speed, water temperature $110^{\circ} \mathrm{C}$ and oil temperature $130^{\circ} \mathrm{C}$. Results were an oil consumption of $48,3 \mathrm{~g} / \mathrm{h}$ and blow by $55,7 \mathrm{l} / \mathrm{min}$. The cold/warm test consists of (100h) with cycle time of $14 \mathrm{~min}$.

2) Engine testing of piston rings with new coating E2 (1st batch) and reference oil SAE 5W30. After 14 hour of hot test running the engine is stopped due to high blow-by. In the engine disassembly it is observed that the E2 coated rings show scuffing and the liners are severely deteriorated.

3) Engine testing of piston rings with new coating E3 and reference oil SAE 5W30. After an initial test failure due to reasons not caused by the new rings, the tested ring set goes successfully under the hot test running $(100 \mathrm{~h})$ and the cold/warm cycles $(100 \mathrm{~h})$. The E3 coated rings show no sign of scuffing and a periphery wear $30 \%$ more than the reference coating. On the contrary the induced liner wear is lower more than $50 \%$.

4) Engine testing of piston rings with new coating E1 and reference oil SAE 5W30 was successfully concluded after hot test running (100h) and cold/warm cycles (100h). The ring periphery wear of E1 is equal to the reference coating and the induced wear in the cylinder is importantly reduced in around $70 \%$. Unfortunately it is observed after the engine disassembly that the top ring of piston no. 4 shows peripheral erosion and breakage.

5) Engine testing of piston rings with new coating E2 (2nd batch) and reference oil SAE 5W30 was successfully concluded after hot test running (100h) and cold/warm cycles (100h). The ring periphery wear of E2 is $80 \%$ higher than the reference coating and the induced wear in the cylinder is reduced in around $40 \%$.

6) Reference engine test with EPC-49 oil: The studied tribological pair is the cylinder liner of $96 \mathrm{~mm}$ internal diameter and made of uncoated pearlitic cast iron AT182 and top piston rings of $96 \mathrm{~mm}$ outside diameter, height $2 \mathrm{~mm}$ and made of nodular graphite cast iron AT126 coated with PL72 standard atmospheric plasma layer. The results are the reference for wear, scuff resistance and adherence with special triboreactive epc- 49 oil.

These tests were performed with the reference materials and using the oil EPC-49. The scuffing test $(2 \mathrm{~h} 30 \mathrm{~m})$ was done with $100 \%$ load and speed engine conditions. Neither piston nor piston rings show scuff marks after testing. Concerning hot test (100h), the engine conditions were $105 \%$ load, $100 \%$ speed, water temperature $110^{\circ} \mathrm{C}$ and oil temperature $130^{\circ} \mathrm{C}$.

7) Engine testing of piston rings with new coating E3 and EPC-49 oil. The tested ring set goes successfully under scuff test $(2.5 \mathrm{~h})$, the hot test running $(100 \mathrm{~h})$ and the cold/warm cycles $(100 \mathrm{~h})$. The E3 coated rings show no sign of scuffing and a periphery wear and cylinder bore induced wear performance similar to the result obtained with the reference components. 


\begin{tabular}{|c|c|c|c|c|c|c|c|c|}
\hline $\begin{array}{l}0 \\
0 \\
0 \\
Z\end{array}$ & 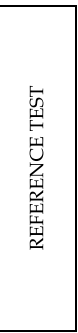 & 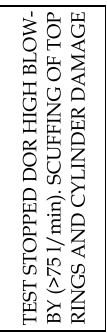 & 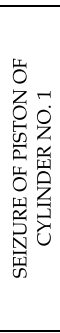 & ठ̆ & 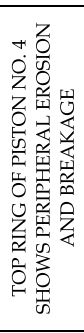 & ठ̌ & б̆ & ठ \\
\hline 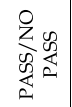 & 岁 & 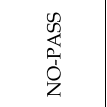 & 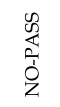 & 总 & 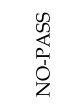 & 足 & 岁 & 岁 \\
\hline 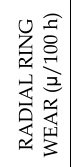 & $\vec{\circ}$ & ' & ' & $\stackrel{M}{\sim}$ & 苛 & $\stackrel{\infty}{\stackrel{\sim}{A}}$ & 今્ & 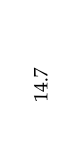 \\
\hline 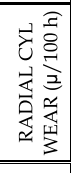 & $\stackrel{\mathscr{c}}{\mathrm{i}}$ & & ' & 0 & $\stackrel{n o}{\circ}$ & $\stackrel{\leftrightarrow}{-}$ & $\overrightarrow{\mathrm{i}}$ & הี \\
\hline 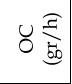 & $\underset{\substack{m \\
\text { ga }}}{ }$ & ' & , & $\tilde{\mathcal{Z}}$ & $\stackrel{m}{\xi}$ & 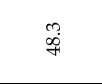 & ڤें & ஜ̊̀ \\
\hline 皛 & 苚 & ' & 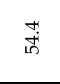 & 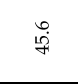 & : & 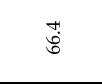 & 苟 & 号 \\
\hline 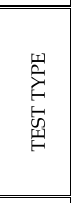 & 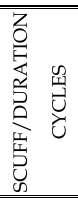 & 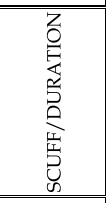 & 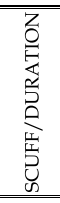 & 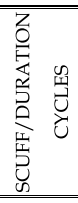 & 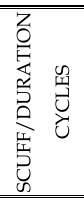 & 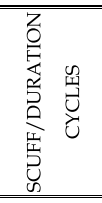 & 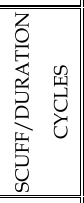 & 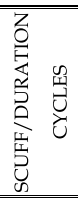 \\
\hline 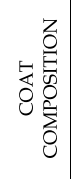 & 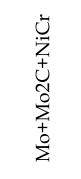 & 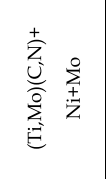 & 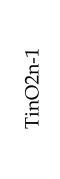 & $\begin{array}{l}\vec{I} \\
\text { Iñ } \\
\text { E } \\
\text { E }\end{array}$ & 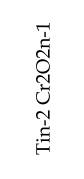 & 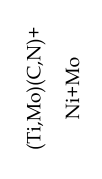 & 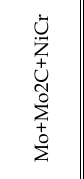 & 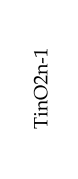 \\
\hline 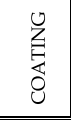 & 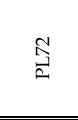 & 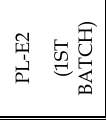 & $\begin{array}{l}\text { 峦 } \\
\text { 岁 }\end{array}$ & 兽 & 离 & 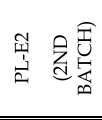 & 忿 & 舀 \\
\hline $\begin{array}{l}0 \\
\text { בे } \\
\end{array}$ & 苛 & ్ָత్య & ت્ચ & 苂 & ్ㅗ & ָָָ & 藏 & $\underset{\mathbb{N}}{\mathbb{N}}$ \\
\hline 하 & 臽 & 㤐 & 息 & 密 & 具 & 具 & 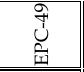 & 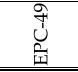 \\
\hline 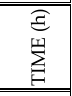 & 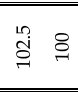 & $\begin{array}{l}\stackrel{n}{2} \\
\stackrel{n}{\sim}\end{array}$ & $\overrightarrow{\mathscr{0}}$ & 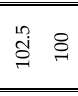 & & 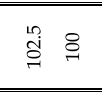 & 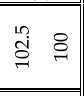 & 님 \\
\hline 蘇 & 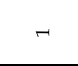 & $N$ & $m$ & 兽 & + & in & 0 & $\wedge$ \\
\hline
\end{tabular}

Table 11. Main Test Results 
In figure 27 the difference between measurements are presented. These values are a combination of the wear and deformation that the components have suffered during the test.

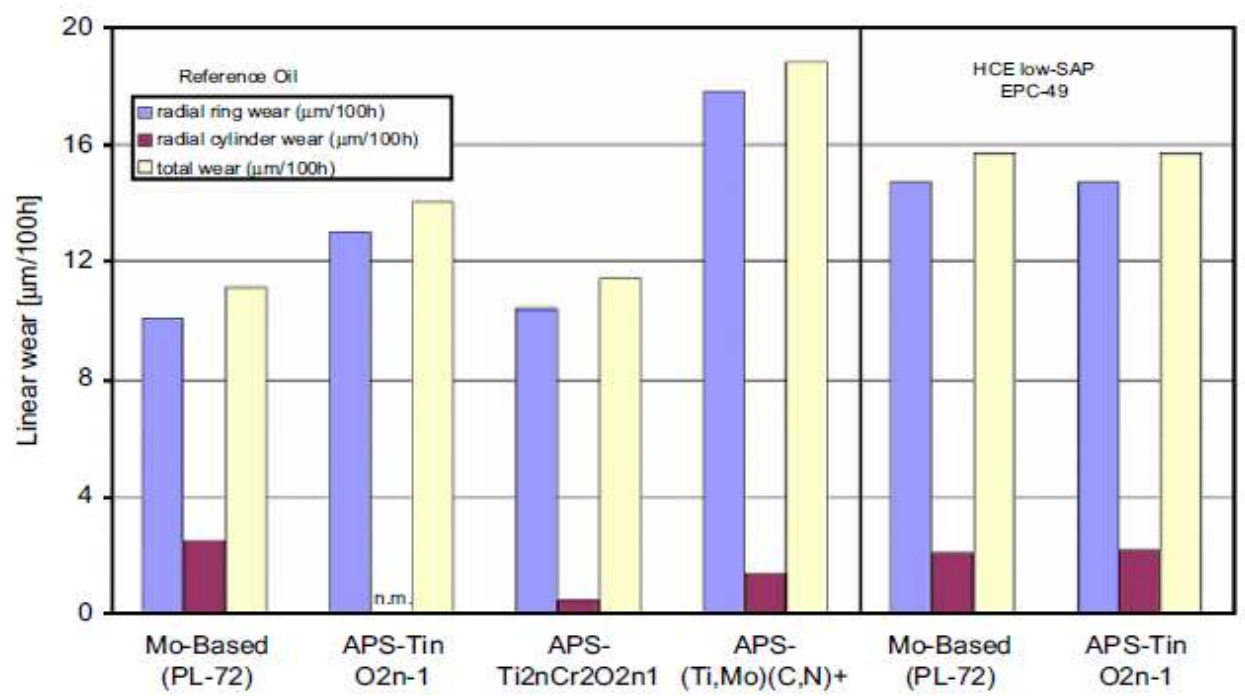

Figure 27. Testing of piston rings in a turbo diesel engine testing arrangement.

\section{Conclusions}

The main conclusions of the tests are summarized as follows:

- Good wear and anti-scuffing properties of Titanium Oxide followed by the (Ti, $\mathrm{Mo})(\mathrm{C}, \mathrm{N})+23 \mathrm{NiMo}$ coatings.

- Wear resistance of TinO2n_1 coating is similar to standard Mo-based coating for both standard and triboreactive oil.

The best extreme pressure properties (in tribological tests) were found for the Titanium Chromium Oxide coating but it was detached from the iron substrate during the engine tests.

Wear results with triboreactive oil EPC-49 are similar to the standard oil, and oil consumption results were reduced by $45 \%$.

\section{Author details}

Amaya Igartua and Xana Fdez-Pérez

Ik4 Tekniker, Spain 
Iñaki Illarramendi

CIE- Tarabusi, Spain

Rolf Luther and Jürgen Rausch

FUCHS, Germany

Mathias Woydt

Bam, Germany

\section{Acknowledgement}

The authors express their gratitude to the European Union for the financial support given to this work through the GROWTH Project no. GRD2-2001-50119, Contract no. G3RD-CT-200200796-EREBIO and the Spanish Minister of Science and Technology reference MAT200211137-E. The authors also would like to thank all the remaining partners from EREBIO project FALEX, CRSA, GUASCOR, RENAULT, FERESPE, BRITO, and INEGI for giving their approval for this publication.

Also the authors give their gratitude to the European Union for the financial support through the seventh framework, Theme 7, Sustainable Surface Transport, POWERtrain for Future Light-duty vehicles, Grant agreement no.: 234032

\section{References}

Igartua, A.; Barriga, J., Aranzabe, A.; (2005) Biodegradable Lubricants. Virtual Tribology Institute Edition, ISBN 83-70204-418-X..

Schmidt, R.; Klingenberg, G., Woydt, M., (2006) Tribological, thermophysical and viscosinetric properties of lubricants interacting with triboactive materials. BAM Research Report 277.

Fitamen, E.; Tiquet, L., Woydt, M., (2006) In: ASTM D02 Symposium on Automotive Lubricants - Testing and Additive Development; 3-5 December 2006.

Desplanches, G.; Criqui, B., Linneman, T., Woydt, M., (2006) Plenary paper al 15th International Colloquium Tribology, TAE Esslingen; 17-19 January 2006.

Rakopoulos, CD.; Antonopoulos, KA., Rakopoulos, DC., (2006) Energy conversion and Management 2006;47(11-12):1550-73.

Ramadhas, AS. ; Muraleedharan, C., Jayaraj, S., (2003) Renewable Energy 2003; 30(12): 1789800.

Miura, M.; (2004) Journal of Japanese Society of Tribologists 2004; 49(10):793-8.

Ulosoy, Y., Tekin, Y., Centinkaya, M., (2004) Energy Sources 2004; 26(10):927-32.

Megahed, OA.; Abadı'a RI, Nabil, D. (2004) Energy Sources 2004; 26(2):119-26.

Tanabe, H.; (2003) Journal of Japanese Society of Tribologists 2003; 48(6):442-6.

Hashimoto, T., (2003) Journal of Japanese Society of Tribologists 2003; 48(4):278-82.

Chen, CI.; (2003) Tribology Letters 2003; 14(2):83-90. 
146 New Advances in Vehicular Technology and Automotive Engineering

Gmble, RJ.; Priest M., Taylor CM., (2003) Tribology letters 2003; 14(2):147-56. 